\title{
Development of Brake Booster Design for Electric City Cars
}

\author{
Afitro Adam Nugraha ${ }^{1}$, Danardono Agus Sumarsono ${ }^{1 *}$, Mohammad Adhitya ${ }^{1}$, \\ Sonki Prasetya ${ }^{1,2}$ \\ ${ }^{1}$ Research Center for Advanced Vehicles (RCAVE), Faculty of Engineering, Universitas Indonesia, Kampus UI \\ Depok, Depok 16424, Indonesia \\ ${ }^{2}$ Mechanical Engineering Department, Politeknik Negeri Jakarta, Kampus Baru Universitas Indonesia, \\ Depok 16424, Indonesia
}

\begin{abstract}
Mekara Electric Vehicle 02 is a type of city car that converts conventional vehicles into electric vehicles at the Universitas Indonesia. The brake booster component system still uses a type of vacuum brake booster. The brake booster is a component in the brake system that reduces the force on the driver's pedal in the vehicle braking process. The vacuum brake booster requires a vacuum generated by the engine intake manifold. In an electric car, there is no vacuum in the intake manifold because the engine is changed by an electric motor. The use of a vacuum brake booster in electric cars requires an additional component of a vacuum pump. The use of a vacuum pump on a vehicle battery requires electricity consumption of 3.9 Watt hours. In this study, we aim to design a new electric brake booster mechanism as a replacement for the vacuum brake booster mechanism. We used our proposed method to design an electric brake booster component and make a prototype. The prototype was tested using a rig test simulation. The electric brake amplifier applies the magnetic force generated by the solenoid and pulls the lever bar connected to the brake master. The brake pedal that is stepped on by the driver activates the flow of electricity on the solenoid and activates a magnetic pull force so that the driver's force in pressing the brake pedal will be assisted by an electric brake booster mechanism. Electric brake boosters can reduce electricity consumption by $28.2 \%$.
\end{abstract}

Keywords: Brake booster; Brake system; Electric brake booster; Electromagnetic brake; Solenoid brake system

\section{Introduction}

According to the World Health Organization (WHO, 2020), 91\% of the world's population is in a bad air environment that exceeds the limits set by the WHO. One of the causes of air pollution is the transportation sector. The greater the emissions produced due to increased production, the farther the distance traveled by a company to distribute its products due to greater energy consumption (Mubarak and Rahman, 2020). Replacing fossil fuel vehicles with electric vehicles is a way to tackle air pollution in the transportation sector (Zulkarnain et al., 2012; Helmers et al., 2017; Zhao et al., 2021).

Universitas Indonesia launched an urban city car-type electric vehicle: Makara Electric Vehicle-02 (MEV-02). The MEV-02 uses an induction motor type with a power of $7.5 \mathrm{~kW}$ and a battery capacity of $102 \mathrm{Ah}$. It can travel at a speed of up to $80 \mathrm{~km} / \mathrm{hour}$. 
The brake system is one of the most important parts for a vehicle to deaccelerate or stop the vehicle (Aleksandrowicz, 2019). City Car MEV-02 UI is a conversion vehicle from fossil fuels to electric vehicles; therefore, the brake booster component system still uses the Vacum Brake Booster type. The vacuum brake booster requires air vacuum generated by the engine intake manifold (Walker et al., 2019), whereas electric cars lack a vacuum in the intake manifold because the engine is converted by an electric motor. To use a vacuum-type brake booster in an electric car, it is necessary to have an additional vacuum pump component (Albrichsfeld and Jürgen, 2009; Berjoza et al., 2016; Chen et al., 2018). Previously, City Car MEV-02 used a 12 DC Electric Vacuum Pump type HDZKB-F1 as an additional component to support the vacuum brake booster component to work. By adding the vacuum pump, an additional $250 \mathrm{~mm} \times 170 \mathrm{~mm} \times 170 \mathrm{~mm}$ space is required on the vehicle, with an additional weight of $2.6 \mathrm{~kg}$. The consumption of using a vacuum pump on the vehicle battery is $3.9 \mathrm{Wh}$. In electric vehicles, the use of battery consumption is very disadvantageous because it is also used by the additional vacuum pump (Prasetya et al., 2020).

Siregar et al. (2020) investigated the causes of brake failure due to friction overheating that occurs in brake components between brake elements due to weight bearing and vehicle speed. Zainuri et al. (2017) explored the transmission system of MEV-02 using the zero shift system. The zero shift system is a transmission that can shift gears without changing periods. Lyu and Jing (2019) studied the brake booster component of the brake system for city cars. The brake booster serves to increase the driver's driving force during braking, thus making the braking process lighter and more comfortable for the driver (Guan et al., 2013; Lyu and Jing, 2019). Without a brake booster, the driver needs more power to step on the brake pedal. This is because the force required by the vehicle when moving is relatively large. In this study, we aim to convert the vacuum-type brake booster system into a new model of an electric brake booster. It uses the solenoid principle as the prime mover. The new brake booster model does not need to add a vacuum pump component. Therefore, it does not require additional space or weight on the vehicle. The battery energy used is expected to be less than using a vacuum pump. The vacuum energy is used as an additional braking force by employing many conversion steps from battery energy to motion energy to create a vacuum. if we can reduce the conversion step only from battery energy to magnetic energy to create an additional braking force, then efficiency can be increased. The existence of this brake booster is expected to provide safety and comfort for drivers in the braking process and increase the efficiency of vehicle battery usage. Furthermore, we conduct a preliminary analysis to design a new electric brake booster alongside test experiments on the electric brake booster prototype. The achievements in this study are expected to reduce space, weight, and energy consumption.

\section{Methods}

Several steps were taken in this study: analyzing the braking force and the force generated by the vacuum-type brake booster on the City Car MEV-02. These steps are necessary to obtain an initial reference for designing an electrical brake booster mechanism for the prototype to be used for the experimental testing on the electric brake booster. This experiment uses a test rig/is not applied to a direct vehicle. Using direct vehicles in the test raises various factors that are difficult in the measurement process, such as time, road conditions, vehicle conditions, and drag coefficient. Table 1 shows the initial measurement of the no-load (no-passenger) MEV-02 vehicle data study. 
Table 1 Specification of city car MEV 02

\begin{tabular}{clcc}
\hline No & \multicolumn{1}{c}{ Item } & Value & Unit \\
\hline 1 & Length of vehicle & 3640 & $\mathrm{~mm}$ \\
2 & Width of vehicle & 1600 & $\mathrm{~mm}$ \\
3 & High of vehicle & 1520 & $\mathrm{~mm}$ \\
4 & Wheelbase & 2455 & $\mathrm{~mm}$ \\
5 & Weight of vehicle & 1011 & $\mathrm{~kg}$ \\
6 & Max. speed of vehicle & 80 & $\mathrm{~km} / \mathrm{h}$ \\
\hline
\end{tabular}

\subsection{Analysis of the MEV-02 Braking Force}

Vehicle weight is measured based on the weight of the vehicle plus the weight of people with different weights (Jung et al., 2008). The measurement samples every weight point of the vehicle wheels (Ko et al., 2016). Table 2 presents the results of measurements of MEV02 vehicles coupled with passengers. These measurements are made by weighing the mass of the vehicle with the mass of each passenger in the passenger position (Figure 1).

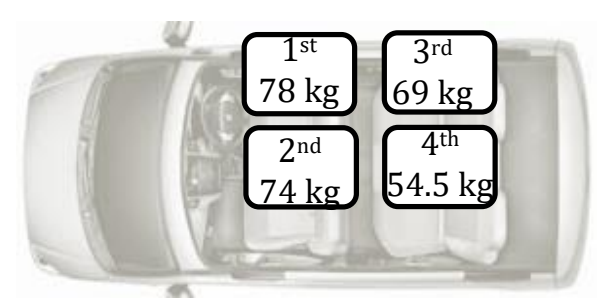

Figure 1 Position of weighing vehicles and passenger masses

Table 2 Weight measurement data in vehicles

\begin{tabular}{clcccc}
\hline No & Weight Distribution & $\begin{array}{c}\text { MEV-02 with one } \\
\text { person }\end{array}$ & $\begin{array}{c}\text { MEV-02 with } \\
\text { two-person }\end{array}$ & $\begin{array}{c}\text { MEV-02 with } \\
\text { three-person }\end{array}$ & $\begin{array}{c}\text { MEV-02 with } \\
\text { four-person }\end{array}$ \\
\hline 1 & Total weight $(\mathrm{kg})$ & 1089 & 1163 & 1232 & 1286.5 \\
2 & Front weight $(\mathrm{kg})$ & 501 & 541.5 & 552 & 565.5 \\
3 & Rear weight $(\mathrm{kg})$ & 588 & 621.5 & 680 & 721 \\
\hline
\end{tabular}

Table 2 is used to calculate the vehicle braking force. Figure 2 presents the weight-free diagram of the vehicle to find the center of gravity vertically.

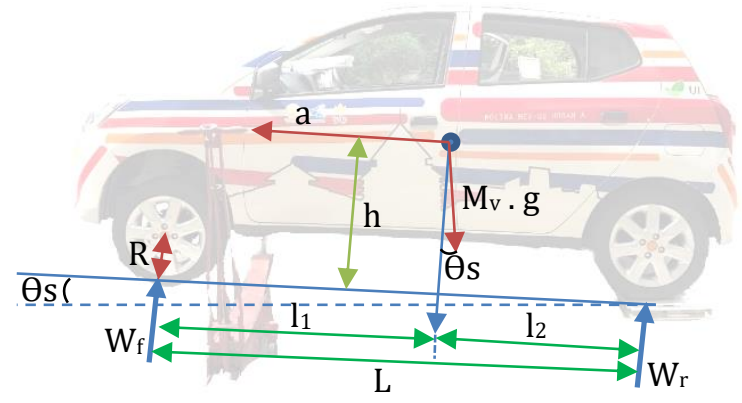

Figure 2 Vehicle weight-free diagram

From Table 1 and Figure 2, the vertical center of gravity (h) can be found using the formula (Ko et al., 2016).

$$
\mathrm{h}=\mathrm{R}+\frac{M_{f}\left(l_{1}+l_{2}\right)-M_{v} \cdot l_{2}}{M_{v} \tan \theta_{s}}
$$

After the vertical center of gravity is gained, an analysis of the braking load on the front and rear wheels of the vehicle can be carried out. This analysis is meant to obtain the total 
braking force of the vehicle at maximum load. Meanwhile, the breaking load of the front wheel ( $\mathrm{W}_{\mathrm{f}}$ ) is found using this formula (Ko et al., 2016).

$$
\mathrm{W}_{\mathrm{f}}=\frac{M_{v g}}{L}\left(l_{2}+\mathrm{h} \frac{a}{g}\right)
$$

This is applied to find the rear wheel braking load $\left(\mathrm{W}_{\mathrm{r}}\right)$ formulas as well.

$$
\mathrm{W}_{\mathrm{r}}=\frac{M_{v g}}{L}\left(l_{1}-\mathrm{h} \frac{a}{g}\right)
$$

Adding these front and rear braking loads results in the total load ( $\left.\mathrm{W}_{\text {total }}\right)$ of the vehicle.

$$
\mathrm{W}_{\text {total }}=\mathrm{W}_{\mathrm{f}}+\mathrm{W}_{\mathrm{r}}
$$

The maximum load of vehicles that are assumed to run on dry asphalt gets a friction coefficient between dry asphalt and vehicle tires of ( $\mu_{\text {est }}$ ) (Matsuzaki et al., 2015) so that it is obtained by the formula:

$$
\mathrm{W}_{\max }=\mu_{\text {est }} \cdot \mathrm{W}_{\text {total }}
$$

\subsection{Analysis of the Calculation of the Braking Force on the MEV-02 Brake Pedal}

MEV-02 uses 175/65 R 14 82T tires type. It means they have a tire radius of 0.292 meters. The amount of braking torque on the disk uses the following formula:

$$
\mathrm{T}_{\mathrm{pi}}=\mathrm{F}_{\text {tire }} \cdot \text { Rtire }
$$

The braking torque on the wheels is transmitted through friction by the brake pad and disk with a cross-sectional area (Apad) of $0.002 \mathrm{~m}^{2}$. The disk used by MEV-02 has a wheel radius $\left(\mathrm{R}_{\mathrm{pi}}\right)$ of $0.169 \mathrm{~m}$. The coefficient of friction $(\mu)$ is assumed to be 0.4 (Kchaou et al., 2013). Then the pressure on the brake caliper required is equal to:

$$
\mathrm{P}_{\mathrm{cal}}=\frac{\mathrm{Tpi}}{2 \cdot \mathrm{Apad} \cdot \mu \cdot \mathrm{Rpi}}
$$

The fluid pressure required by the brake caliper $\left(\mathrm{P}_{\text {cal }}\right)$ to press the brake pad is the same as the pressure from the brake master $\left(\mathrm{P}_{\mathrm{c}}\right)$ through the brake hose (Söderberg and Sören, 2009). In Figure 3, the force transmitted after the brake booster is $\left(F_{c}\right)$ will push the piston on the brake master to suppress the fluid. The force that continues after the brake booster is $F_{c}$ and is obtained using the following formula:

$$
\mathrm{F}_{\mathrm{c}}=\mathrm{P}_{\mathrm{cal}} \cdot \mathrm{Am}_{\mathrm{m}}
$$

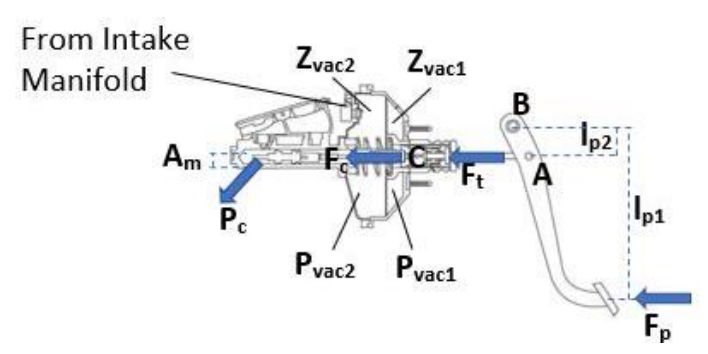

Figure 3 The process of transferring the braking force from the pedal to the brake caliper

The force acting on the lever of $F_{t}$ is passed on to the brake master and activates the brake booster vacuum mechanism so that it works (Yu et al., 2016). The working principle of a brake booster vacuum is to help increase the force by leveraging the pressure difference (Mason and Williams, 2002). The pressure difference is in the $\mathrm{Z}_{\mathrm{vac} 1}$ and $\mathrm{Z}_{\mathrm{vac}}$ spaces in Figure 3. When the pedal is pressed, atmospheric air enters the $\mathrm{Z}_{\mathrm{vac} 1}$ space for $\mathrm{P}_{\mathrm{vac}}$. Concurrently, in the $Z_{\text {vac2 }}$ room, it is connected to the intake manifold so that the amount of pressure on the $\mathrm{Z}_{\mathrm{vac} 2}$ will be the same as the pressure in the intake manifold of $\mathrm{P}_{\mathrm{vac} 2}$. The vacuum force 
of the brake booster is also influenced by a large cross-sectional area in the brake booster chamber as big as $A_{v a c}$. The magnitude of the force in $F_{t}$ is

$$
F_{t}=F_{c}-\left(\left(P_{v a c 1}-P_{v a c}\right) \times A_{v a c}\right)
$$

The driver's force on the pedal whose Fp is forwarded through the lever at point $A$ is multiplied by the hinge at point $\mathrm{B}$, which is obtained by the formula.

$$
\mathrm{F}_{\mathrm{p}}=\frac{F_{t \cdot l p 1}}{l p 2}
$$

\subsection{Calculation of the Design of the Electric Brake Booster Component}

The eddy current principle is applied to the electric brake booster component. Eddy currents are induced currents that move in a magnetic field or can be called Fauccoult currents (Yaguchi et al., 2019). Hence, the number (N) of copper wire coils wrapped around the iron core along (l) and cross-sectional area (A) will produce a magnetic force (B) and function as a bar magnet when energized by an electric current (I). The magnitude of the magnetic field at the endpoint of the iron wrapped around the celluloid wire is obtained by the formula (Prasetya et al., 2020).

$$
\mathrm{B}=\frac{\mu . N . I}{2 l}
$$

The permeability of the vacuum $\left(\mu_{0}\right)$ is $4 \pi \times 10^{-7}$, and the relative permeability of iron $\left(\mu_{\mathrm{r}}\right)$ is 144 (Lu et al., 2019). The permeability of the material can be found using the formula $\mu=\mu_{0} . \mu_{\mathrm{r}}$. Therefore, the permeability of the material $(\mu)$ used is $1.884 \times 10^{-4}$. The amount of torque $(\tau)$ generated from the design of the solenoid brake booster component to assist in the vehicle braking process is obtained by the formula (Yaguchi et al., 2019).

$$
\tau=\mathrm{B} \cdot \mathrm{I} \cdot \mathrm{A} \cdot \mathrm{N}
$$

The electrical energy needed by the electric brake booster at work $(\mathrm{P})$ with electric current (I) and resistance wire of solenoid (R) can be seen in the following formula (Zhao et al., 2017).

$$
\mathrm{P}=\mathrm{I}^{2} \cdot \mathrm{R}
$$

\subsection{Calculation of the Forces on the Electric Brake Booster Component}

The forces that work between the electric brake booster components are very simple: using the force arm principle (Mason and Williams, 2002). The forces that occur can be seen in Figure 5.

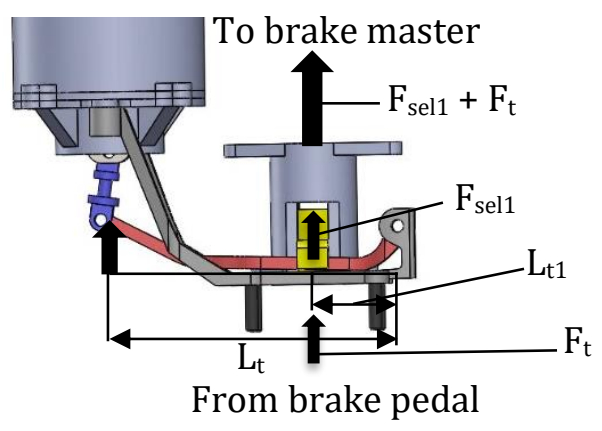

Figure 5. The forces acting on the electric brake booster component

In Figure 5 , the magnitude of the force $\left(F_{\text {sel1 }}\right)$ transmitted by the magnet coil force forwarded by the driver lever is obtained from the formula.

$$
\mathrm{F}_{\mathrm{sel} 1}=\frac{F_{\text {sel } 2 . L t_{2}}}{L_{t 1}}
$$


The electric brake booster style will function to replace the vacuum brake booster, which is forwarded to the brake master.

\section{Results and Discussion}

\subsection{Design Analysis}

Figure 6 shows the data with various loads, from containing one person to a maximum of four people with a specified weight of people, and then processed using Equations 1-5 so that the results of the vehicle braking load are obtained.

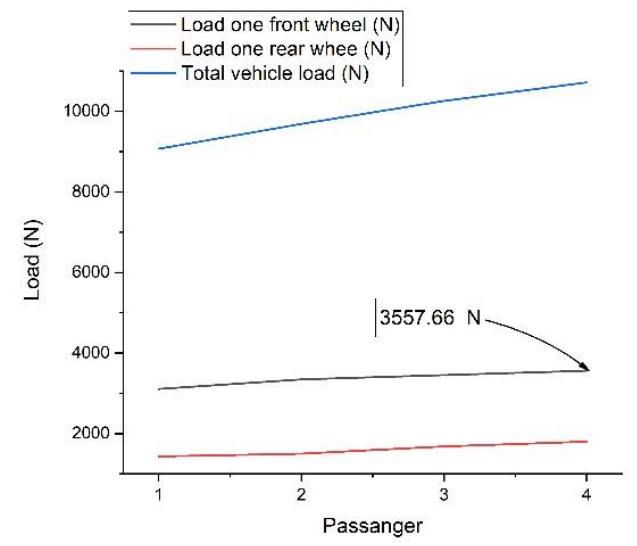

Figure 6 Graph of braking force on vehicles against the number of passengers

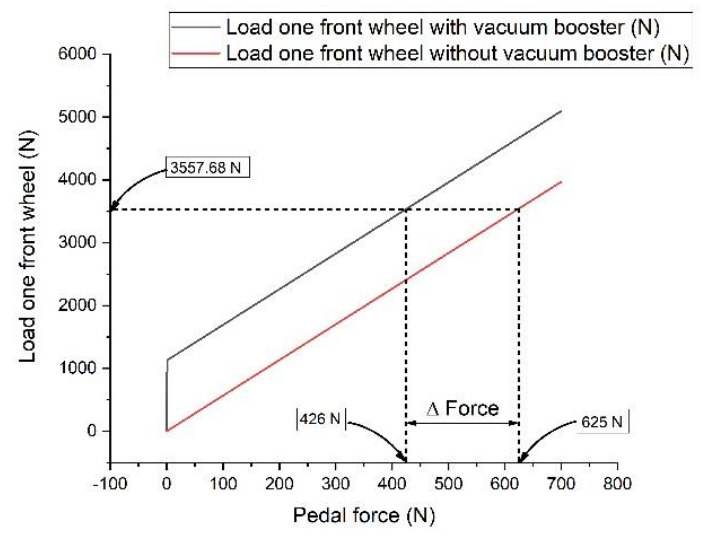

(a)

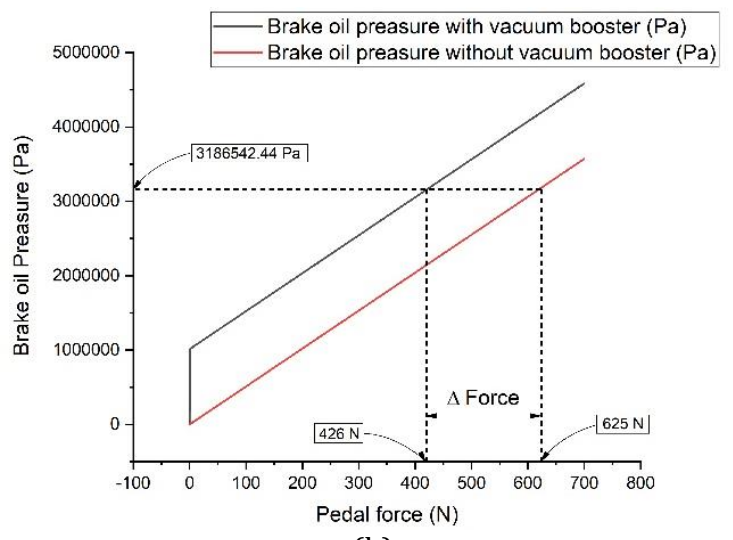

(b)

Figure 7 (a) Graph of pedal force and braking force of one front tire; (b) Graph of pedal force and brake oil pressure

Figure 7 is obtained from the results of the analysis calculations in Equations 6-10. Figure 7 shows the magnitude of the forces acting on the brake system using a vacuum brake booster and without using a vacuum brake booster. To achieve a force on the front wheels of $3557.68 \mathrm{~N}$ from Figure $7 \mathrm{a}$ and oil pressure of $3.2 \times 10^{6}$ from Figure $7 \mathrm{~b}$, it takes the driver's compressive force of $426 \mathrm{~N}$ aided by a vacuum brake booster and $625 \mathrm{~N}$ without a vacuum brake booster. In this case, the trampling force of the driver could be 1.48 times lighter than needed. The brake booster auxiliary force required is $496.41 \mathrm{~N}$, so the design required for the electric brake booster requires a torque of $64.53 \mathrm{Nm}$. Figure 8 shows the voltage and electric current needed to activate the magnetic field by the torque required. 


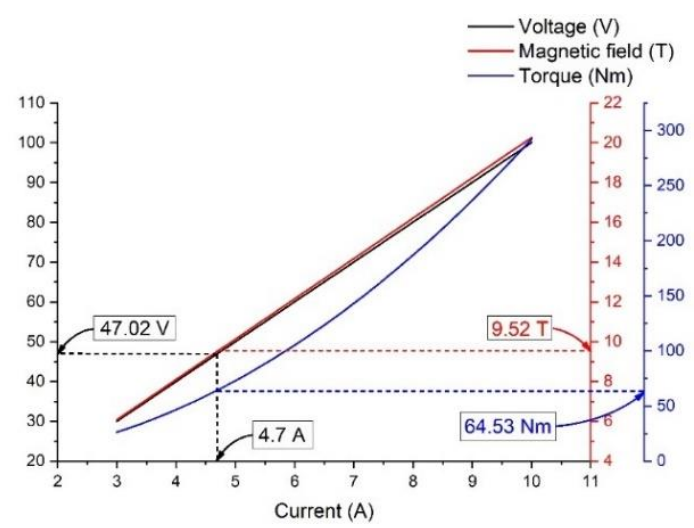

Figure 8 Graph of the current and voltage that will be used to activate the solenoid

Figure 8 is obtained from the results of the calculation analysis using the Equations 11, 12 , and 14. Figure 8 shows a graph of the amount of current, voltage, magnetic field, and torque produced by the designed solenoid component. To activate the same magnetic torque, the resulting vacuum brake booster is $64.53 \mathrm{Nm}$; the required amount of electric current is $4.7 \mathrm{~A}$ and a voltage of $47.02 \mathrm{~V}$. From the measurement data on MEV-02 and the analysis results from the calculation of existing theories, the process of electric component design is shown in Table 3. From the calculation analysis using Equation 13, the power of the electric brake booster is $176.72 \mathrm{~W}$.

Table 3 Electric brake booster design specifications

\begin{tabular}{clcc}
\hline No & \multicolumn{1}{c}{ Item } & Value & Unit \\
\hline 1 & Total length & 247.62 & $\mathrm{~mm}$ \\
2 & Total wide & 232.63 & $\mathrm{~mm}$ \\
3 & Total high & 174.42 & $\mathrm{~mm}$ \\
4 & Total weight & 4.6 & $\mathrm{~kg}$ \\
5 & Solenoid wire diameter & 1 & $\mathrm{~mm}$ \\
6 & Solenoid inside diameter & 50 & $\mathrm{~mm}$ \\
7 & Length of solenoid & 67.5 & $\mathrm{~mm}$ \\
\hline
\end{tabular}

This design is made with a simple lever principle for transferring the solenoid magnetic field force to the brake master. The components are made very simple so that their manufacturing and assembly processes will be easy. Regarding maintenance, it is sufficient to check whether the lubrication is still sufficient on surfaces that are rubbing together.
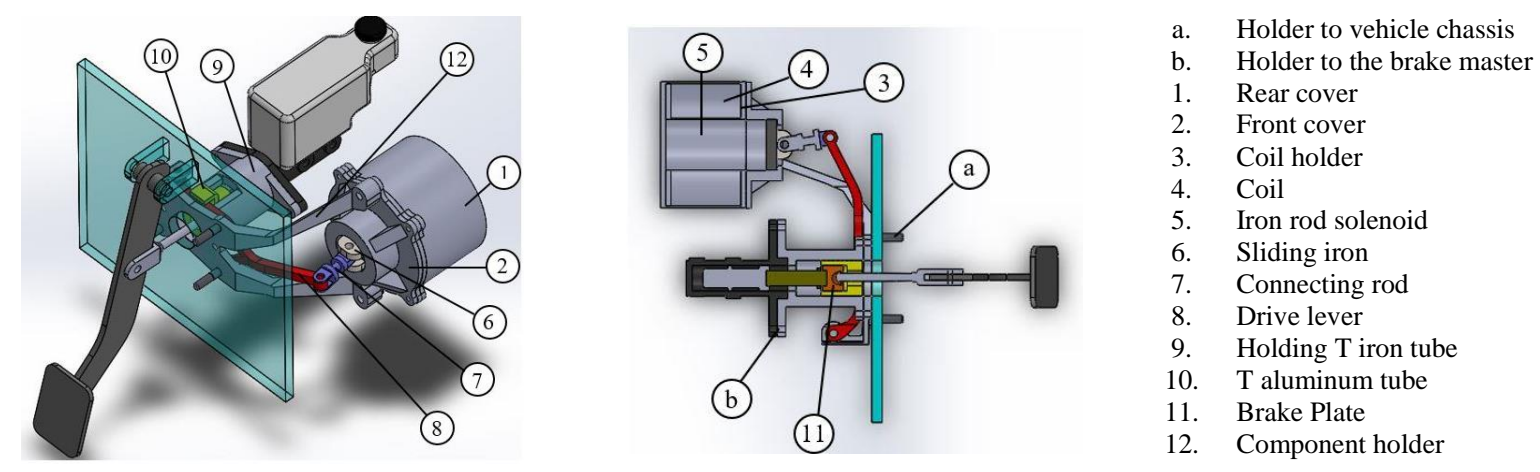

Figure 9 Electric brake booster design

This design is made uncomplicated so that it will be very easy in the disassembly process. Figure 9 presents the design of the solenoid brake booster. Figure 9 shows the 
design of the electric brake booster along with the number and names of the components needed.

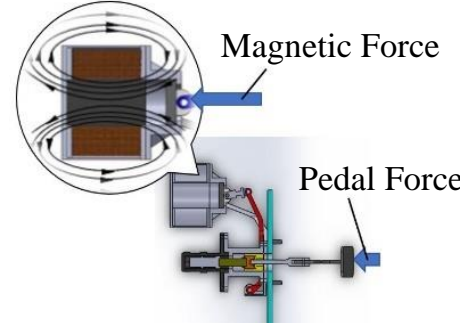

(a)

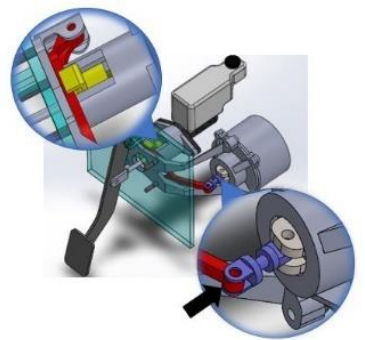

(b)

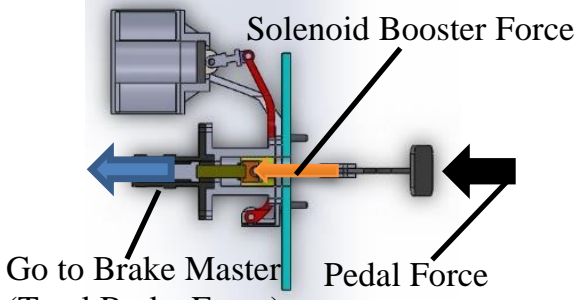

(Total Brake Force)

Figure 10 (a) Active solenoid; (b) Host force at work; (c) Solenoid brake booster when working

Figure 10 shows how the electric brake booster design works. In Figure 10, when the driver steps on the brake pedal, there is an active switch, which gives a signal to the controller. The controller will process the data and channel the current from the battery. The current from the battery, which is supplied to the coil of the wire, will produce a magnetic force (Figure 10a). The magnetic force that occurs on the solenoid iron rod will attract the sliding iron. The plate iron connected to the drive lever through the connecting rod will move and press the $\mathrm{T}$ aluminum tube in Figure 10b. The moving aluminum tube will push the brake plate so that it helps the braking process (Figure 10c).

\subsection{Electric Brake Booster Prototype and the Rig Test}

Figure 11a is a prototype image of the electric brake booster component that was made. The electric brake booster to be tested requires a test rig that is suitably constructed like the original vehicle.

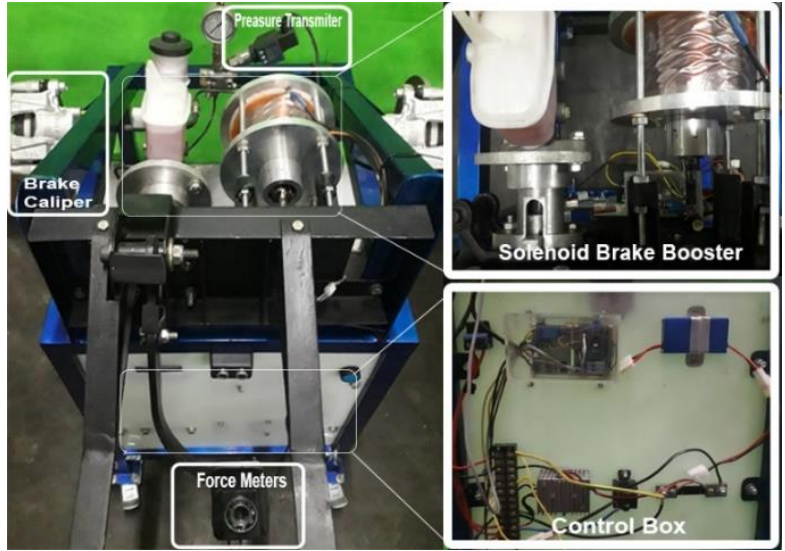

(a)

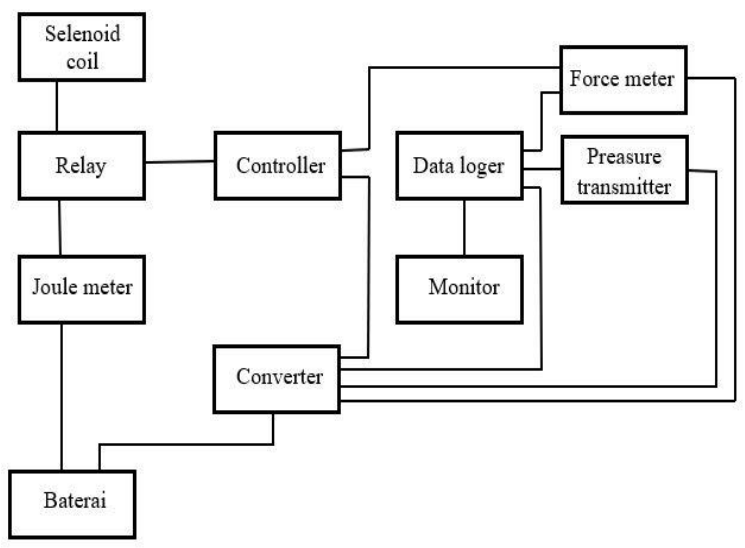

(b)

Figure 11 (a) Electric brake booster prototype and rig test; (b) flow chart of the electric brake booster test simulator

In Figure $11 \mathrm{~b}$, a battery with a capacity of $48 \mathrm{~V} 10 \mathrm{Ah}$ is passed through the joule meter to analyze the amount of current, voltage, and battery consumption used by the electric brake booster at work. After the joule meter passes through the relay and goes straight to the coil on the design prototype component of the electric brake booster that is designed, one more path from the battery to the converter from $48 \mathrm{~V}$ to $5 \mathrm{~V}$ is used for the electric brake booster controller, the data logger, the pressure transmitter, and the force meter. The electric brake booster controller functions to control the amount of incoming voltage and receives an incoming signal from the force meter to activate the electric brake booster when the brake pedal is pressed. The pressure transmitter is a brake oil pressure sensor that 
occurs during braking. The force meter determines the traction force of the driver during the braking process and sends a signal to the controller to activate the electric brake booster. Input data from the joule meter, measurement transmitter, and force meter are processed by the data logger and displayed on a computer monitor.

\subsection{The Results of the Electric Brake Booster Experiment}

Figure 12 is a graph of the data results from the prototype electric brake booster test. To validate the experiment, eight data samples were taken from the braking state without using an electric brake booster and eight times using an electric brake booster.

Figure 12 shows the average of the results of all experiments performed. Linier fit line is a line to linearize the graph due to irregular pressure frequencies. For the function equation of the experiment conducted: $y=3.31 x^{2}+6157.76-401468.73$ with r-square (COD) of 0.99706 without electric brake booster, and $y=4.67 x^{2}+6682.65 x-240283.66$ with r-square (COD) of 0.99648 for using an electric brake booster.

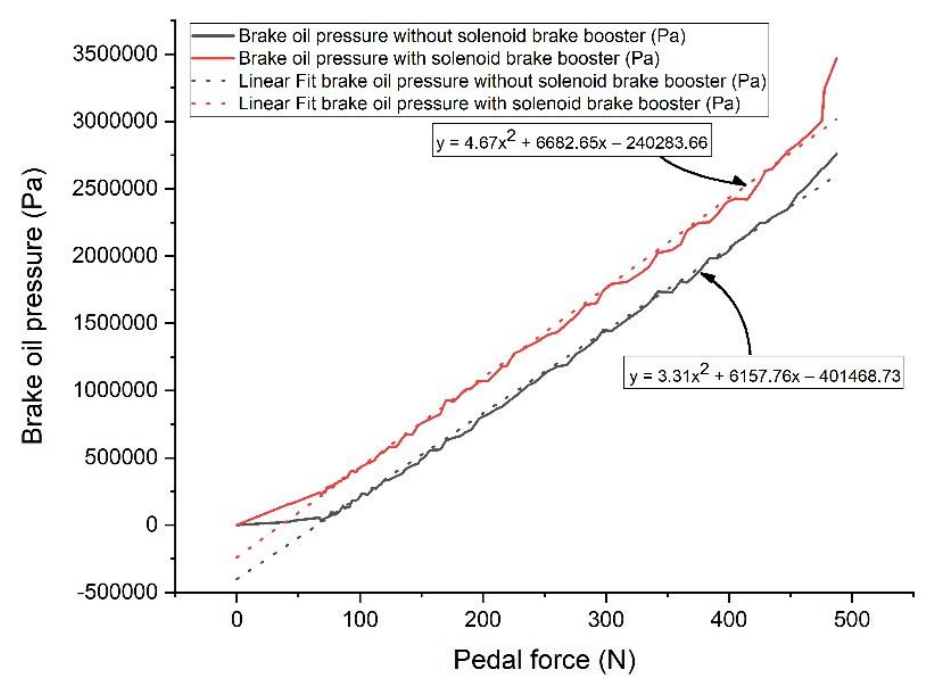

Figure 12 Graph of pedal style and brake oil pressure regarding the experimental electric brake booster

In Figure 12, the brake oil pressure required in the braking process is maximum at $3.19 \times 10^{6}$, which requires a pedal force without a brake booster of $467.42 \mathrm{~N}$ and using an electric brake booster of $401.92 \mathrm{~N}$ on the brake pedal footing. In this case, the trampling force of the driver could be 1.16 times lighter than needed.

The average voltage used by the electric brake booster is $49.64 \mathrm{~V}$, and the average current used is $5.05 \mathrm{~A}$, with the resistance of the electric brake booster component being 8 $\Omega$. The battery consumption required to use the electric brake booster is $2.8 \mathrm{Wh}$. This design requires less electrical energy from the battery than using a vacuum pump with a battery consumption of $3.9 \mathrm{Wh}$.

\section{Conclusions}

The electric brake booster is designed for City Car MEV-02 with a maximum vehicle weight of $1286 \mathrm{~kg}$ and a maximum vehicle speed of $80 \mathrm{~km} /$ hour. The design of the electric brake booster mechanism uses magnetic force with the principle of the electrified solenoid. Electric brake booster cuts the energy conversion steps used in the previous system on the MEV-02 UI vehicle. The use of electric power-assisted braking only converts battery electrical energy into electromagnetic energy as a driving force for the driver when braking. Electric brake booster is designed to replace the vacuum brake booster and does not 
require additional volume from the vacuum pump. Electric power-assisted braking has a total volume of $1.004 \times 10^{-2} \mathrm{~m}^{3}$ which can reduce the volume of the vacuum brake booster and vacuum pump by $1.32 \times 10^{-2} \mathrm{~m}^{3}$. The total mass of the previous vacuum brake booster and vacuum pump is $5.7 \mathrm{~kg}$. Electric brake booster is $4.8 \mathrm{~kg}$ so that it can reduce weight from the previous one. Electric brake booster of $2.8 \mathrm{Wh}$ replaces a vacuum pump that consumes 3.9 Wh of electricity, so it can save battery electricity by $28.2 \%$.

\section{Acknowledgements}

The author would like to thank the Universitas Indonesia, Depok, Indonesia, for financial support under the Research Grant Program for International Indexed Publication Students in Technology and Health 2020 (NKB-2448/UN2.RST/HKP.05.00/2020) and Publikasi terindeks International (PUTI NKB-645/UN2.RST/HKP.05.00/2020).

\section{References}

Albrichsfeld, V.C., Jürgen K., 2009. Brake System for Hybrid and Electric Vehicles. SAE Technical Papers, pp. 1-7

Aleksandrowicz, P., 2019. The Impact of a Vehicle Braking System State on Safe Driving. Part Two. AIP Conference Proceedings, Volume 2077(1), https://doi.org/10.1063/1.5091862

Berjoza, D., Pirs, V., Dukulis, I., Jurgena, I., 2016. Development and Analysis of a Driving Cycle to Identify the Effectiveness of the Vacuum Brake Booster. Agronomy Research, Volume 14(3), pp. 672-682

Chen, P., Wu, J., Zhao, J., He, Rui., 2018. Design and Position Control of a Novel Electric Brake Booster. SAE International Journal of Passenger Cars - Mechanical Systems, Volume 11(5), pp. 1-11

Guan, H., Weituo, H., Jun, Z., 2013. A Vacuum Booster Model for Brake Pedal Feeling Analysis. Advanced Materials Research, Volume 622-623, pp. 1248-1252

Helmers, E., Johannes, D., Susanne, H., 2017. Electric Car Life Cycle Assessment based on Real-World Mileage and the Electric Conversion Scenario. International Journal of Life Cycle Assessment, Volume 22(1), pp. 15-30

Jung, S.P., Jun, K.J., Park, T.W., Yoon, J.H., 2008. Development of the Brake System Design Program for a Vehicle. International Journal of Automotive Technology, Volume 9(1), pp. 45-51

Kchaou, M., Sellami, A., Elleuch, R., Singh, H., 2013. Friction Characteristics of a Brake Friction Material under Different Braking Conditions. Materials and Design, Volume 52, pp. 533-540

Lu, M., Huang, R., Yin, W., Zhao, Q., Peyton, A., 2019. Measurement of Permeability for Ferrous Metallic Plates using a Novel Lift-off Compensation Technique on Phase Signature. IEEE Sensors Journal, Volume 19(17), pp. 440-446

Lyu, D., Jing L., 2019. EBooster: A Technology That Improves the Efficiency of Brake Recuperation in Electric Vehicle. In: Proceedings - 2019 Chinese Automation Congress, CAC 2019, pp. 5712-5716

Mason, C., Williams, V., 2002. ASE 5 - Brakes Power Brake Boosters. Power Break Boosters. International Association GM ASEP/BSEP General Motor Corporation

Matsuzaki, R., Kamai, K., and Seki, R. Intelligent tires for identifying coefficient of friction of tire/road contact surfaces using three-axis accelerometer, Smart Mater. Struct., vol. 24, no. 2, 2015. doi.org/10.1117/12.2083158.

Mubarak, A., Rahman, I., 2020. A Comparative Analysis of Carbon Emissions from 
Transportation and Logistics of the Consumer Goods Industry in Southeast Asia. International Journal of Technology, Volume 11(2), pp. 333-341

Prasetya, S., Budiono, H.D.S., Baskoro, A.S., Shamsuddin, A., Sumarsono, D.A., Adhitya, M., Zainuri, F., Nazaruddin, Heryana, G., Siregar, R., 2020. Smart Braking Actuator Control for a Heavy Weighted Electric Vehicle. Journal of Mechanical Engineering Research and Developments, Volume 44(1), pp. 8-16

Ko, S., Song, C., Kim, H., 2016. Cooperative Control of The Motor and Electric Booster Brake to Improve the Stability of An In-Wheel Electric Vehicle. International Journal of Automotive Technology, Volume 17(3), pp. 447-456

Siregar, R., Adhitya, M., Sumarsono, D.A., Nazaruddin, Heryana, G., Zainuri, F., 2020. Study the Brake Performance of a Passenger Car Based on the Temperature That Occurs in Each Brake Unit. Recent Progress on: Mechanical, Infrastructure and Industrial Engineering. In: Proceedings of International Symposium on Advances in Mechanical Engineering (ISAME): Quality in Research 2019 2227, 020013

Söderberg, A., Sören A., 2009. Simulation of Wear and Contact Pressure Distribution at the Pad-to-Rotor Interface in a Disc Brake using General Purpose Finite Element Analysis Software. Wear, Volume 267(12), pp. 2243-2251

Walker, J., Robert, R., Dan, B., Steven, K., 2019. Brake Vacuum Booster Characterization. SAE Technical Papers, pp. 1-7

World Health Organization (WHO), 2020. Air Pollution. Available Online at www.who.int. https://www.who.int/Health-Topics/Air-Pollution\#tab=tab_1

Yaguchi, H., Toshiki, M., Kazumi, I., 2019. A New Type of Magnetic Pump with Coupled Mechanical Vibration and Electromagnetic Force. Journal of Mechanical Engineering and Sciences, Volume 13(3), pp. 5212-5227

Yu, L., Xiaohui, L., Xiaoxue, L., 2016. Analysis of Energy Consumption on Typical Main Cylinder Booster Based Brake-by-Wire System. SAE Technical Papers, pp. 1-8

Zainuri, F., Danardono, A., Sumarsono, M. A., Rolan, S., 2017. Design of Synchromesh Mechanism to Optimization Manual Transmission's Electric Vehicle. AIP Conference Proceedings, Volume 1823(1), https://doi.org/10.1063/1.4978104

Zhao, J., Wang, M., Wang, Z., Grekhov, L., Qiu, T., Ma, X., 2017. Different Boost Voltage Effects on the Dynamic Response and Energy Losses of High-Speed Solenoid Valves. Applied Thermal Engineering Volume 123, pp. 1494-1503

Zhao, J., Xi, X., Na, Q., Wang, S., Kadry, S.N., Kumar, P.M., 2021. The Technological Innovation of Hybrid and Plug-in Electric Vehicles for Environment Carbon Pollution Control. Environmental Impact Assessment Review, Volume 86, https://doi.org/10.1016/j.eiar.2020.106506

Zulkarnain, Teppo, K., Pekka, L., Mikko, T., 2012. Electric Vehicles Market Outlook Potential Consumers, Information Services and Sites Test. International Journal of Technology, Volume 3(2), pp. 156-168 